\title{
Efficacy of Hepatoprotective Agents With or Without Antiviral Drugs on Liver Function and Fibrosis in Patients With Hepatitis B: A Meta-Analysis
}

\author{
Li-Hui Long ${ }^{1, *}$; Cai-Qin Xue ${ }^{1}$; Jun-Feng Shi ${ }^{1}$; Juan-Ni Dong ${ }^{1}$; Li Wang $^{2}$ \\ ${ }^{1}$ Department of Pharmacy, the First Affiliated Hospital of Xi'an Medical College, Xi'an, Shaanxi 710077, China \\ ${ }^{2}$ Research Division, the First Affiliated Hospital of Xi'an Medical College, Xi'an, Shaanxi 710077, China \\ *Corresponding Author: Li-Hui Long, Department of Pharmacy, the First Affiliated Hospital of Xi'an Medical College, Xi'an, Shaanxi 710077, China. Tel: $+86-2984277599$, \\ Fax: +86-2984277599, E-mail: llhbjd@126.com
}

Received: April 11, 2015; Revised: May 17, 2015; Accepted: May 31, 2015

\begin{abstract}
Context: To systematically evaluate the effects of hepatoprotective agents, when delivered either alone or in combination with other antiviral or non-antiviral drugs in patients with hepatitis B and hepatic fibrosis.

Objectives: The current randomized controlled clinical trials aimed to evaluate the efficacy of combinations of antiviral and non-antiviral hepatoprotective agents on indexes of liver function and liver fibrosis in patients with hepatitis $B$.

Data Sources: Published literatures in Chinese and English on hepatoprotective treatment strategies for chronic hepatitis B and liver fibrosis were searched in three databases and randomized controlled clinical trials were selected.

Study Selection: Data were extracted according to a variety of inclusion and exclusion criteria. Meta-analysis was employed to analyze the data.

Results: A total of 22 randomized controlled trials encompassing 1,714 cases were considered in the meta-analysis. The obtained results indicated that the combination of antiviral drug and hepatoprotective agent was better than antiviral drug alone to improveliver function. Similarly, regarding liver fibrosis, using two different hepatoprotective agents was better than using one agent. The normalization rates of Aminotransferase (ALT) and total Bilirubin (TBil) were improved $25.7 \%$ by two hepatoprotective agents compared to the single agent. Acetylcysteine was superior to ursodeoxycholic acid or silibinin to reduce ALT. Ursodeoxycholic acid was superior to acetylcysteine or silibinin to reduce TBIL.

Conclusions: Hepatoprotective agents combined with antiviral drugs can significantly improve liver function and liver fibrosis parameters in patients with hepatitis $B$.
\end{abstract}

Keywords: Hepatitis B; Liver Cirrhosis; Meta-Analysis; Ursodeoxycholic Acid (UDCA); Silibinin; Acetylcysteine

\section{Context}

At present, Hepatitis B Virus (HBV) infection is an important public health problem worldwide. Hepatitis $\mathrm{B}$ can lead to serious liver diseases, including cirrhosis, liver cancer. In China, approximately 120 million people are infected with the Hepatitis B Virus (1). Alavian et al. reported that about 1 million people are infected with HBV in Iran, and 15\% to $40 \%$ of the patients with hepatitis B may develop cirrhosis or liver cancer (2). Liver fibrosis is a healing response, but the excessive accumulation of extracellular matrix (ECM) components in the liver often leads to severe forms of liver fibrosis, and ultimately cirrhosis with liver dysfunction (3-5). Early cirrhosis may be reversible. Therefore, prompt diagnosis and intervention are critical in limiting disease progression (6). Clinically, the existing hepatoprotective agents include Ursodesoxycholic acid (UDCA), silibinin, and N-acetylcysteine (NAC). UDCA is a hydrophilic bile acid, which alters the ratio of hydrophilic-to-hydrophobic components in the bile acid pool. It promotes the secretion of endogenous bile acids such as chenodeoxycholic and lithocholic acid, and im- proves cholestasis. UDCA is mainly used to treat primary biliary cirrhosis, hepatitis B associated liver fibrosis, and cholestatic liver disease, the efficacy is certain. Some studies reported that UDCA protects liver cell membrane and enhances immune function. These mechanisms may be related to the ability of ursodeoxycholic acid to regulate cell cycle, apoptosis and protein biosynthesis of liver cells. Alternatively, the increased pool of hydrophilic bile acid and the stability of the cell membrane may play an important protective role $(7,8)$. UDCA, which causes minimal damage and is non-toxic to liver cells, is an effective hepatoprotective agent and cholagogue (9). Results of long-term observational studies showed that ursodeoxycholic acid can significantly reduce the development of hepatic fibrosis $(8,10,11)$.

Silibinin is derived from milk thistle, an important medicinal plant that is roots, leaves and seeds exert a variety of therapeutic effects, including hepatoprotective, antioxidant, and anti-lipogenic properties (12). In the United States and Europe, about $65 \%$ of patients with liver dis-

Copyright (C) 2015, Kowsar Corp. This is an open-access article distributed under the terms of the Creative Commons Attribution-NonCommercial 4.0 International License (http://creativecommons.org/licenses/by-nc/4.0/) which permits copy and redistribute the material just in noncommercial usages, provided the original work is properly cited. 
ease use Chinese medical preparations which include milk thistle as their most common ingredient (13). Silymarin, a mixture of flavonoids and wood ester pigment compounds, is extracted from milk thistle seeds. Silymarin contains silibinin, silychristin, and silymarin Ning with a large amount of silibinin. it is noteworthy that, silibinin is the main active ingredient of silymarin (14). In recent years, silibinin has been used to treat liver cirrhosis, hepatitis, liver fibrosis and alcoholic liver disease (15).

$\mathrm{N}$-acetylcysteine (NAC) is an intracellular glutathione precursor, which can enhance the activity of glutathione transferase and promote the detoxification of free radicals. nitric oxide (NO) and its metabolite can improve microcirculation, increase tissue oxygen, and enhance the repair of damaged tissue $(16,17)$. In recent years, clinical studies have demonstrated that NAC is not only effective to treat liver failure caused by excessive acetaminophen (paracetamol), but is also useful for liver disease arising from other causes (18). NAC reduces serum Total Bilirubin (TBil) and aminotransferases, and increases Prothrombin activity (PTA) in patients with severe chronic hepatitis B (19).

\section{Objectives}

The current study aimed to search randomized controlled clinical trials to evaluate the efficacy of antiviral and non-antiviral hepatoprotective agents combinations on the indexes of liver function and liver fibrosis in patients with hepatitis $B$.

\section{Data Sources}

Papers written in either English or Chinese describing the use of hepatoprotective agents to treat hepatitis and liver fibrosis were retrieved. Using "chronic hepatitis B, hepatitis B, HBV, liver fibrosis, hepatoprotective, silibinin (silymarin, silybin meglumine), acetylcysteine and ursodeoxycholic bile acid (UDCA)", the study retrieved papers indexed in the China national knowledge internet (CNKI) (2000 - 2012), Pubmed (19832013), Embase (2000 - 2013) and Cochrane databases (1992-2012).

\section{Study Selection}

\subsection{Inclusion and Exclusion Criteria}

\subsubsection{Inclusion Criteria}

Hepatitis B infection or liver fibrosis; chronic hepatitis B was diagnosed if HBV history or HBV markers were persistently positive for more than six months and serum alanine aminotransferase levels exceeded $80 \mathrm{IU} / \mathrm{L}$, and hepatic fibrosis was estimated by indexes containing the following markers: HA, LN, C-IV, PIIIP (13). Results indicators including Alanine Aminotransferase (ALT), Aspartate Aminotransferase (AST), TBIL, gamma-Glutamyl Transpeptidase ( $\gamma$-GGT), Alkaline Phosphatase (ALP), Hyaluron- ic acid (HA), Laminin (LN), Collagen type IV (CIV), and Procollagen III peptide (PIIIP). Trials were limited to those comparing the efficacy of different drugs or placebo.

\subsubsection{Exclusion Criteria}

Studies in which non-protective liver drugs were used to treat viral hepatitis or liver fibrosis; animal experiments and reviewed papers that did not contain clinical data; pregnant and lactating female patients with liver disease. The therapy course was less than three weeks; liver biochemical markers were normal.

\subsection{Outcome Indicators}

Outcomes were reported in terms of efficacy as follows: 1) Markedly effective: patients underwent full recovery or exhibited significant improvements in their clinical symptoms; levels of ALT, AST, GGT, TBIL and other basic indicators of liver function were restored to within the normal range. 2) Effective: moderate improvement of clinical symptoms, signs and liver function. 3) Ineffective: no obvious improvement or exacerbation of symptoms, signs and liver function indexes.

\subsection{Statistical Analysis}

RevMan5.2 software was used to analyze the data. For classified data, risk ratio (RR) and 95\% confidence interval (95\% CI) were used. For continuous data, weighted mean difference (WMD) and 95\% CI were used. If I2 < $50 \%$, the test was considered uniform with no statistically significant heterogeneity, the fixed effects model was used if $\mathrm{I} 2>50 \%$, a random effects model was used. A Funnel plot was used to evaluate possible publication bias.

\section{Data Extraction}

Two authors discussed all data sets before extracting them from the published literature. To avoid subjective bias, names of the authors, publications, year, and country were omitted during the data extraction process. Retrieved data included: (1) liver biochemical indicators: ALT (U/L), GGT (U/L), ALP (U/L) and TBIL (U/L); (2) liver fibrosis markers: HA ( $\mu \mathrm{g} / \mathrm{L}), \mathrm{LN}(\mu \mathrm{g} / \mathrm{L}), \mathrm{IV}-\mathrm{C}(\mu \mathrm{g} / \mathrm{L})$ and PIIIP $(\mu \mathrm{g} / \mathrm{L})$. Disagreements were resolved by discussion and consensus.

\section{Results}

\subsection{Retrieval Results}

Initially, 245 papers were retrieved by screening the title, abstract, and inclusion and exclusion criteria. Finally, 22 standard randomized controlled trials were included, with a total of 1,756 subjects, among whom 893 subjects were in the treated group, and 821 subjects were in the control group (Table 1). 
Table 1. Basic Characteristics of the Included Studies ${ }^{\text {a }}$

\begin{tabular}{|c|c|c|c|c|c|c|}
\hline \multirow[t]{2}{*}{ Included Studies } & \multicolumn{2}{|c|}{ Cases } & \multicolumn{2}{|c|}{ Intervening Measures } & \multirow{2}{*}{$\begin{array}{l}\text { Course of } \\
\text { Treatment }\end{array}$} & \multirow{2}{*}{$\begin{array}{l}\text { Efficacy of } \\
\text { Indicators }\end{array}$} \\
\hline & $\begin{array}{l}\text { Experi- } \\
\text { mental } \\
\text { Group }\end{array}$ & $\begin{array}{l}\text { Control } \\
\text { Group }\end{array}$ & Experimental Group & Control Group & & \\
\hline Xia et al. (20) & 58 & 57 & $\begin{array}{l}\text { NAC }(8 \mathrm{~g} / \mathrm{d})+\text { basic } \\
\text { treatment }\end{array}$ & $\begin{array}{c}\text { Basic treatment (Potassium } \\
\text { magnesium aspartate } 2 \\
\mathrm{~g} / \mathrm{d}+\text { promote the liver cell } \\
\text { auxin } 0.1 \mathrm{~g} / \mathrm{d}+\text { plasma } 200 \\
\text { ml qod + other symptom- } \\
\text { atic and supportive treat- } \\
\text { ments) }\end{array}$ & $30 \mathrm{~d}$ & TBIL \\
\hline Shi et al. (21) & 20 & 20 & $\begin{array}{l}\text { NAC }(8 \mathrm{~g} / \mathrm{d})+\text { basic } \\
\text { treatment }\end{array}$ & $\begin{array}{l}\text { Basic treatment (Vitamin } \\
\text { K } 10 \mathrm{mg} / \mathrm{d}+\text { promote the } \\
\text { liver cell auxin } 20 \mathrm{mg} / \mathrm{d} \\
\text { + plasma } 200 \mathrm{ml} \text { qod } \\
\text { or albumin } 10 \mathrm{~g} \text { qod + } \\
\text { ranitidine } 150 \mathrm{mg} \text { po tid } \\
\text { + other symptomatic and } \\
\text { supportive treatments) }\end{array}$ & $45 \mathrm{~d}$ & ALT, AST, TBIL \\
\hline Wang et al. (19) & 50 & 25 & $\begin{array}{c}\mathrm{NAC}(8 \mathrm{~g} / \mathrm{d})+\mathrm{GSH}(1.2 \\
\mathrm{g} / \mathrm{d})\end{array}$ & GSH $(1.2 \mathrm{~g} / \mathrm{d})$ & $28 \mathrm{~d}$ & ALT, AST, TBIL \\
\hline Shohrati et al. (22) & 18 & 20 & $\begin{array}{c}\mathrm{NAC}(1.2 \mathrm{~g} / \mathrm{d})+\text { basic } \\
\text { treatment }\end{array}$ & $\begin{array}{l}\text { Basic treatment (lamivu- } \\
\begin{array}{c}\text { dine + pegylated interferon } \\
+ \text { adefovir })\end{array}\end{array}$ & $45 \mathrm{~d}$ & $\begin{array}{l}\text { ALT, AST, ALP, } \\
\text { TBIL }\end{array}$ \\
\hline Wu et al. (23) & 72 & 72 & $\begin{array}{l}\mathrm{NAC}(8 \mathrm{~g} / \mathrm{d})+\text { basic } \\
\text { treatment }\end{array}$ & $\begin{array}{l}\text { Basic treatment (Vitamin } \\
\mathrm{K} 10 \mathrm{mg} / \mathrm{d}+\text { promote the } \\
\text { liver cell auxin } 20 \mathrm{mg} / \mathrm{d} \\
\text { + plasma } 200 \mathrm{ml} \mathrm{qod} \\
\text { or albumin } 10 \mathrm{~g} \text { qod + } \\
\text { ranitidine } 150 \mathrm{mg} \text { po tid } \\
\text { + other symptomatic and } \\
\text { supportive treatments) }\end{array}$ & $45 \mathrm{~d}$ & ALT, AST, TBIL \\
\hline Wang et al. (24) & 42 & 42 & $\begin{array}{c}\operatorname{UDCA}(0.5 \mathrm{~g} / \mathrm{d})+\mathrm{GSH} \\
(1.2 \mathrm{~g} / \mathrm{d})\end{array}$ & Yinzhihuang (30 ml/d) & $8 w$ & $\begin{array}{l}\text { ALT, GGT, ALP, } \\
\text { TBIL }\end{array}$ \\
\hline Fabris et al. (25) & 40 & 39 & $\begin{array}{c}\operatorname{UDCA}(0.6 \mathrm{~g} / \mathrm{d})+ \\
\text { lactulose }(100-200 \\
\mathrm{g} / \mathrm{d})\end{array}$ & Lactulose $(100-200 \mathrm{~g} / \mathrm{d})$ & $3 w$ & $\begin{array}{l}\text { ALT, AST, GGT, } \\
\text { ALP, TBIL }\end{array}$ \\
\hline Angulo et al. (26) & 21 & 16 & UDCA (13 - 15 mg/kg/d) & $\begin{array}{l}\text { D-penicillamine (the dos- } \\
\text { age was unclear) }\end{array}$ & $24 \mathrm{w}$ & AST, TBIL \\
\hline Cao et al. (27) & 53 & 47 & $\begin{array}{l}\text { UDCA }(0.75 \mathrm{~g} / \mathrm{d})+\text { Ade- } \\
\text { methionine }(1.0 \mathrm{~g} / \mathrm{d})\end{array}$ & $\begin{array}{l}\text { Kuhuang injection (60 } \\
\mathrm{ml} / \mathrm{d})\end{array}$ & $4 \mathrm{w}$ & $\begin{array}{l}\text { ALT, GGT, ALP, } \\
\text { TBIL }\end{array}$ \\
\hline Qureshi et al. (28) & 18 & 12 & $\operatorname{UDCA}(0.5 \mathrm{~g} / \mathrm{d})$ & Placebo (unclear) & $12 \mathrm{w}$ & ALT \\
\hline Ratziu et al. (29) & 62 & 64 & $\operatorname{UDCA}(0.5 \mathrm{~g} / \mathrm{d})$ & Placebo (unclear) & $48 \mathrm{w}$ & $\begin{array}{l}\text { ALT, AST, GGT, } \\
\text { TBIL }\end{array}$ \\
\hline Tkacz et al. (12) & 45 & 15 & Silibinin $(0.42 \mathrm{~g} / \mathrm{d})$ & Placebo (unclear) & $45 \mathrm{~d}$ & ALT, AST, TBIL \\
\hline Flisiak et al. (30) & 15 & 16 & Misoprostol (0.8 g/d) & Silibinin $(0.21 \mathrm{~g} / \mathrm{d})$ & $12 \mathrm{w}$ & ALT, TBIL \\
\hline Flisiak et al. (31) & 25 & 25 & $\begin{array}{l}\text { Silibinin }(0.21 \mathrm{~g} / \mathrm{d})+ \\
\text { misoprostol }(0.8 \mathrm{~g} / \mathrm{d})\end{array}$ & Placebo (unclear) & $24 \mathrm{w}$ & $\begin{array}{l}\text { ALT, AST, GGT, } \\
\text { TBIL }\end{array}$ \\
\hline Gu et al. (32) & 33 & 32 & $\begin{array}{l}\text { Silibinin }(0.6 \mathrm{~g} / \mathrm{d})+ \\
\text { oxymatrine }(0.6 \mathrm{~g} / \mathrm{d})\end{array}$ & Silibinin $(0.6 \mathrm{~g} / \mathrm{d})$ & $12 \mathrm{w}$ & ALT, TBIL \\
\hline Bao et al. (33) & 42 & 42 & $\begin{array}{l}\text { Silibinin }(0.36 \mathrm{~g} / \mathrm{d})+ \\
\text { Interferon } \alpha-16(300 \\
\text { million } \mathrm{U} \text {, q.o.d.) }\end{array}$ & $\begin{array}{l}\text { Interferon } \alpha-16 \text { (300 mil- } \\
\text { lion } U \text {, qod.) }\end{array}$ & $12 \mathrm{w}$ & ALT, AST \\
\hline Bao et al. (34) & 86 & 86 & $\begin{array}{l}\text { Silibinin }(0.36 \mathrm{~g} / \mathrm{d})+ \\
\text { Lamivudine }(0.1 \mathrm{~g} / \mathrm{d})\end{array}$ & Lamivudine $(0.1 \mathrm{~g} / \mathrm{d})$ & $48 \mathrm{w}$ & $\begin{array}{l}\text { ALT, AST, ALP, } \\
\text { TBIL }\end{array}$ \\
\hline
\end{tabular}


Long L et al.

\begin{tabular}{|c|c|c|c|c|c|c|}
\hline Kim et al. (35) & 42 & 43 & $\begin{array}{l}\text { UDCA }(0.6 \mathrm{~g} / \mathrm{d})+\text { Can- } \\
\text { desartan }(0.008 \mathrm{~g} / \mathrm{d})\end{array}$ & Candesartan $(0.008 \mathrm{~g} / \mathrm{d})$ & $24 \mathrm{w}$ & $\begin{array}{l}\text { ALT, AST, GGT, } \\
\text { TBIL }\end{array}$ \\
\hline Wang et al. (36) & 45 & 44 & $\begin{array}{l}\text { Silibinin }(0.315 \mathrm{~g} / \mathrm{d}) \\
+ \text { protect liver treat- } \\
\text { ment + Lamivudine } \\
(0.1 \mathrm{~g} / \mathrm{d})\end{array}$ & $\begin{array}{l}\text { Protect liver treatment } \\
\text { (energy mixture, inosine, } \\
\text { salvia miltiorrhiza, pro- } \\
\text { moting liver cell growth } \\
\text { hormone and vitamin })+ \\
\text { Lamivudine }(0.1 \mathrm{~g} / \mathrm{d})\end{array}$ & NA & $\begin{array}{l}\text { HA, PC, CIV, } \\
\text { LN }\end{array}$ \\
\hline Wu et al. (37) & 40 & 40 & $\begin{array}{c}\text { UDCA (13-15 mg/kg/d) } \\
\text { + Fuzhenghuayu } \\
\text { Capsules }(4.5 \mathrm{~g} / \mathrm{d})\end{array}$ & $\begin{array}{l}\text { Fuzhenghuayu Capsules } \\
\qquad(4.5 \mathrm{~g} / \mathrm{d})\end{array}$ & $48 \mathrm{w}$ & $\begin{array}{l}\text { ALT, AST, GGT, } \\
\text { TBIL, ALP, HA, } \\
\text { LN, IVC, PIIIP }\end{array}$ \\
\hline Mao et al. (38) & 36 & 34 & $\begin{array}{c}\text { Tanshinone }(0.06 \mathrm{~g} / \mathrm{d}) \\
\text { + Oxymatrine }(0.6 \\
\mathrm{g} / \mathrm{d})\end{array}$ & Tanshinone (0.06 g/d) & $4 w$ & $\begin{array}{l}\text { ALT, AST, } \\
\text { TBILI, HA, LN, } \\
\text { PIIIP, IVC }\end{array}$ \\
\hline Zhou et al. (39) & 30 & 30 & $\begin{array}{l}\text { Valsartan }(0.08 \mathrm{~g} / \mathrm{d})+ \\
\quad \text { Silibinin }(0.14 \mathrm{~g} / \mathrm{d})\end{array}$ & Silibinin $(0.14 \mathrm{~g} / \mathrm{d})$ & $12 \mathrm{w}$ & $\begin{array}{l}\text { HA, LN, IV-C, } \\
\text { PIIIP }\end{array}$ \\
\hline
\end{tabular}

a Abbreviations: ALT, Alanine aminotransferase Aminotransferase; ALP; alkaline Alkaline phosphatase Phosphatase; AST, aspartate Aspartate aminotransferase Aminotransferase; CIV collagen Collagen type IV; HA, hyaluronic Hyaluronic acid Acid; LN, laminin Laminin; PIIIP, procollagen Procollagen III peptide Peptide; TBIL, total bilirubin; $\gamma$-GGT, gamma-glutamyl Glutamyl transpeptidase Transpeptidase

\subsection{Treatment Type}

The meta-analysis groups were: 1 ) liver protective drug plus antiviral drug versus antiviral drug alone to assess efficacy of altering ALT, AST, ALP and TBIL levels (Table 1 ; Figure 1);2) liver protective drug (treatment group) versus placebo to assess protective effects in terms of ALT and TBIL (Table 1 ; figures 3 and 4); 3) combination of two hepatoprotective agents versus a single agent in terms of ALT, AST, ALP, GGT, TBIL (Table 1 ; Figure 4); 4) one protective agent versus another in terms of normalization rates of ALT and TBIL (Table 1; Figure 5); 5) evaluation of the effects of a combination of two kinds of protective agents versus a single protective agent in terms of HA, LN, IV-C and PIIIP (Table 1; figures 6 and 7) as hepatic fibrosis markers.

\subsection{Hepatoprotective Drug Combined With Antivi- ral Drug vs. Antiviral Drug Alone}

Six randomized controlled trials reported on the use of a hepatoprotective drug in combination with an antiviral agent treatment of chronic hepatitis $B$. The test and control groups included 741 and 645 subjects, respectively. There was a statistically significant heterogeneity between the studies ( $\mathrm{I} 2>50 \%$ ), and hence, a randomeffects model was used. Meta-analysis showed that using a combination of hepatoprotective and antiviral drugs was more effective than a single antiviral agent to reduce serum levels of ALT, AST, ALP and TBIL. ALT (WMD =-22.98; 95\% CI (-34.98, -10.97)), AST (WMD= -26.20; 95\% CI [-44.60, $-7.81])$, ALP (WMD = -56.19; 95\% CI [-85.27, -27.11]) and TBIL $(\mathrm{WMD}=-5.58 ; 95 \% \mathrm{CI}[-9.50,1.66])$ (Figure 1).

\subsection{Hepatoprotective Agents vs. Placebo}

Five randomized controlled clinical trials reported the effects of three hepatoprotective agents compared with placebo on liver function indexes in patients with chronic hepatitis B, including ALT and TBIL. In these tri- als, the control and treatment groups included 144 and 140 subjects, respectively; since there was no significant heterogeneity between the studies (I $<50 \%$ ), a fixed effect model was applied. Meta-analysis showed that all three hepatoprotective agents significantly decreased ALT levels in patients with hepatitis B. NAC was associated with greater efficacy compared to UDCA and silibinin. The impact of UDCA and silibinin on ALT levels in patients with hepatitis B were considerable: NAC (WMD = -25.66; $\mathrm{P}=0.0002,95 \% \mathrm{CI}[-39.02,-12.31]), \mathrm{UDCA}(\mathrm{WMD}=-22.32 ; \mathrm{P}$ $=0.03,95 \% \mathrm{CI}[-42.28,-2.36])$, silibinin $(\mathrm{WMD}=-22.40 ; \mathrm{P}=$ $0.11,95 \%$ CI [-49.52, 4.72]) (Figure 2).

UDCA was superior over NAC and silibinin to reduce TBIL in patients with hepatitis B. Meta-analysis showed that NAC (WMD = -2.56; P = 95\% CI [-4.95, -0.17]), UDCA $(\mathrm{WMD}=-3.48 ; 95 \% \mathrm{CI}[-7.37,-0.31])$, silibinin $(\mathrm{WMD}=$ -2.09 ; 95\% CI [-8.70, 4.52]). However, the differences were not statistically significant (I2 = 0\%) using a fixed-effects model (Figure 3).

\subsection{Two Kinds of Hepatoprotective Agents vs. a Single Hepatoprotective Agent}

Five randomized controlled clinical trials were employed to test the efficacy of two hepatoprotective agents compared to only one to treat patients with chronic hepatitis B. There were 618 subjects in the two hepatoprotective agents, and the single hepatoprotective agent groups, respectively. The heterogeneity between the studies was statistically significant (I2>50\%). Using a random effects model, meta-analysis showed that the two hepatoprotective agents group was better than the single agent to reduce ALT, AST, GGT, ALP and TBIL levels in patients with hepatitis B. ALT (WMD=-31.44; 95\% CI [-48.57,-14.32]), AST $(\mathrm{WMD}=-14.54 ; 95 \% \mathrm{CI}[-29.24,0.16])$, GGT $(\mathrm{WMD}=-26.98$; 95\% CI [-54.66, 0.70]), ALP (WMD = -29.86; 95\% CI [-52.65, $-7.07])$, TBIL (WMD = -4.84; 95\% CI [-9.86, 0.18]) (Figure 4). 
Figure 1. Meta-Analysis Forest Plots for Effects on ALT, AST, ALP and TBIL Levels

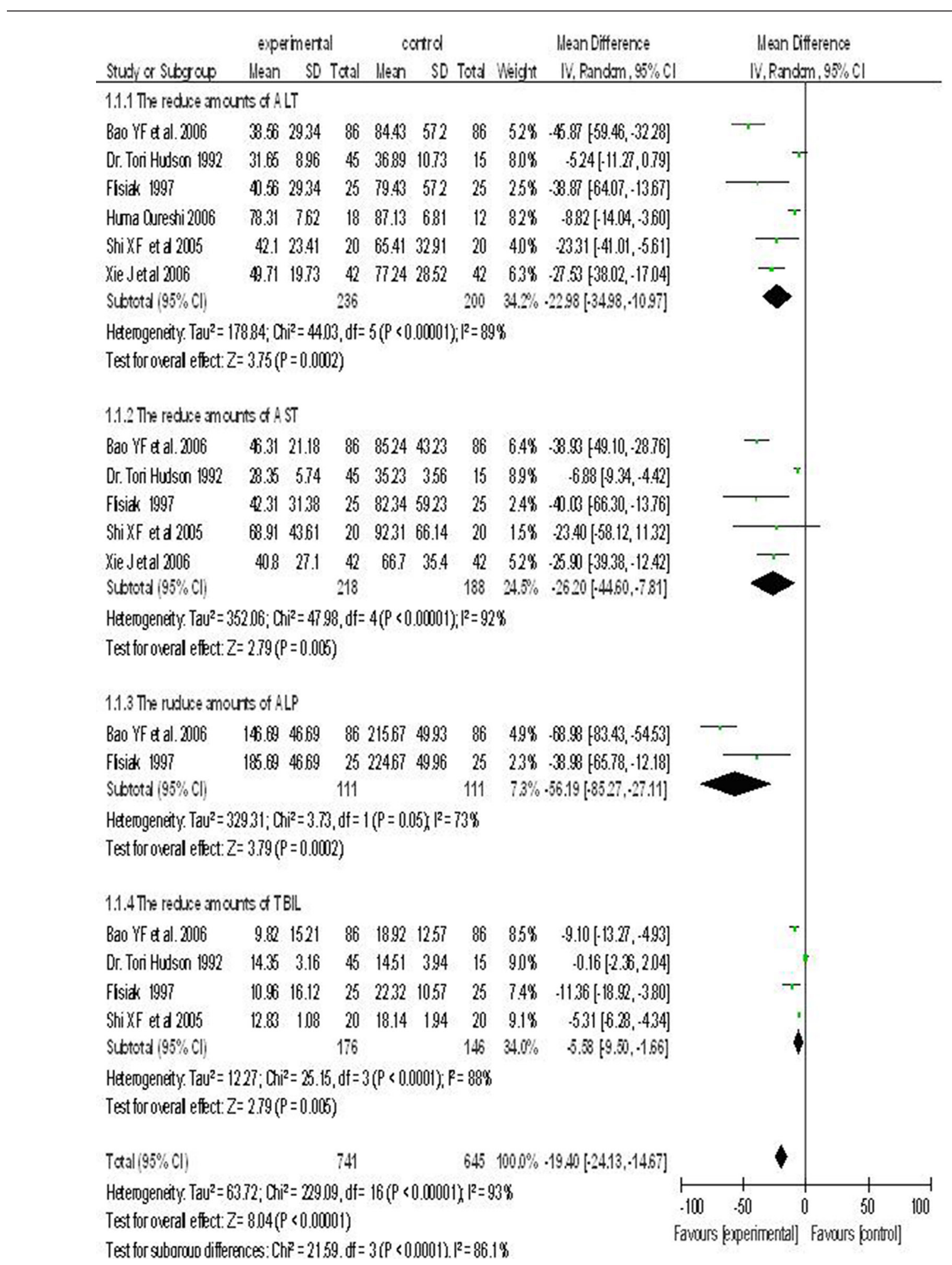

In patients with chronic hepatitis B infection treated with combination hepatoprotective and antiviral drug vs. antiviral drug alone. Data are presented as pooled mean difference using a random-effects model and $95 \%$ confidence intervals. 


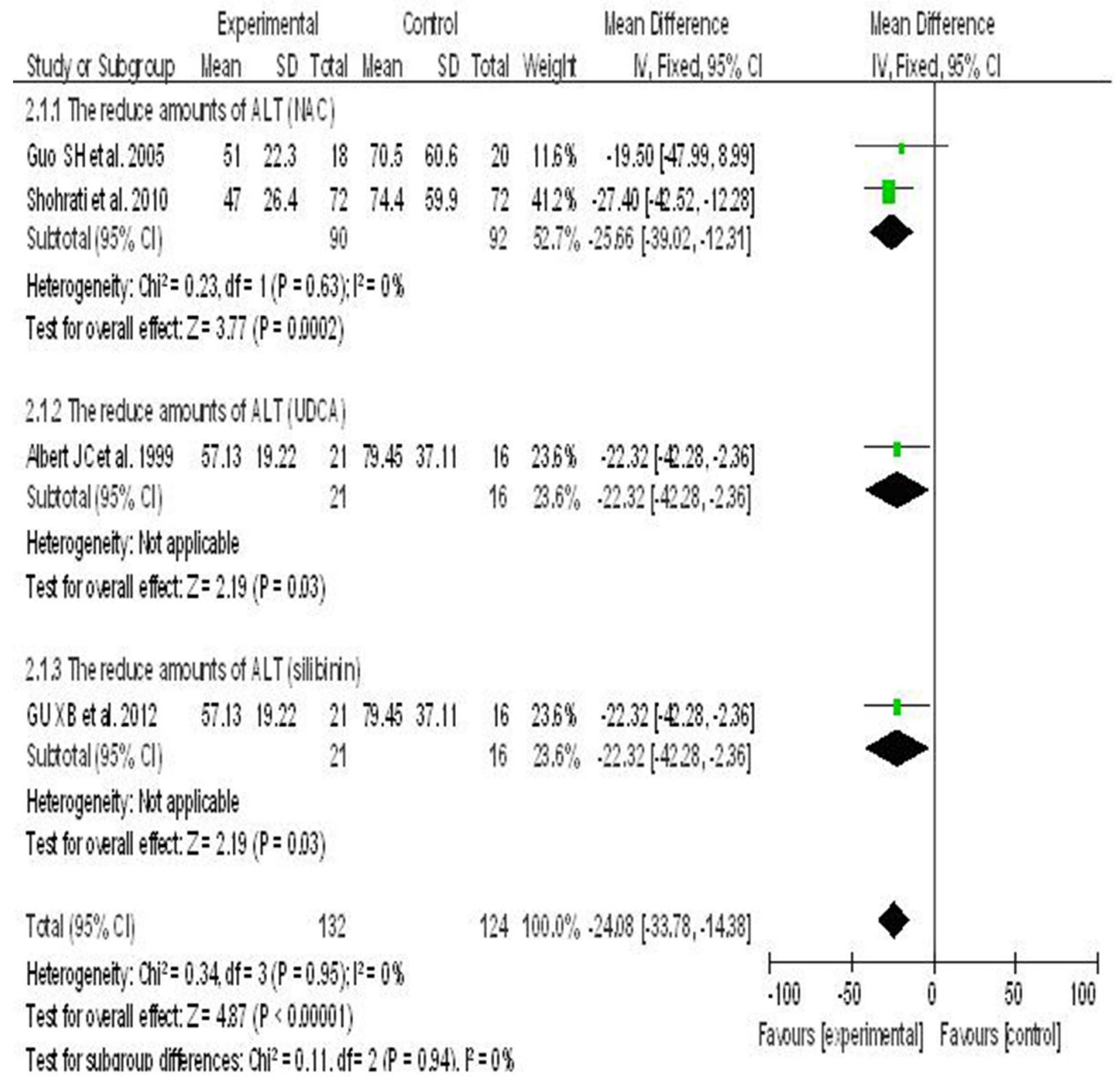

In patients with chronic hepatitis B infection treated with hepatoprotective drugs vs. placebo. Data are presented as pooled mean difference using a random-effect model and $95 \%$ confidence intervals.

6.6. Effects of two Versus one Hepatoprotective Agent on Recovery of Liver Function in Patients With Hepatitis $B$

Three randomized controlled clinical trials reported the effects of combining two hepatoprotective drugs compared to a single agent on the recovery rate of liver indicators in patients with hepatitis B; 173 subjects who used a combination of two agents were compared to 123 subjects who used only one agent. The heterogeneity between the studies was statistically significant (I2 $=0 \%$, P
$=0.98$ ). Therefore, a fixed-effects model was used. Compared with the single agent group, meta-analysis showed that using a combination of two hepatoprotective drugs was more effective than only one in restoring liver indicators to normal levels (two hepatoprotective agents group vs. single hepatoprotective agent group $=75.2 \%$ vs. $49.5 \%)$. $\operatorname{ALT}(72.3 \%$ vs. $48.7 \%, \mathrm{RR}=1.44,95 \% \mathrm{CI}[1.01,2.04]), \operatorname{TBIL}(77.8 \%$ vs. $50 \%, \mathrm{RR}=1.53,95 \% \mathrm{CI}[1.21,1.95])$. The recovery rate of the group that used two hepatoprotective agents was $25.7 \%$ higher than the one treated by a single agent, $(\mathrm{RR}=$ $1.50, \mathrm{P}<0.0001,95 \% \mathrm{CI}[1.23,1.83]$ ) (Figure 5). 
Figure 3. Meta-Analysis Forest Plots Describing the Effects of Hepatoprotective Agents vs. Placebo on TBIL Levels

\section{Experimental Contrd Hean Ditferenoes Hean Citference}

Studyor Sutrgroup Wean SD Tatal Hean SO Tatal Weight NV, Fxed, $5 \%$ Cl $\quad$ V, Fixed, $95 \% \mathrm{Cl}$

3.1.1 The reduce amourts of TBLL (IHA C)

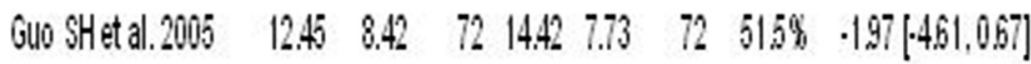

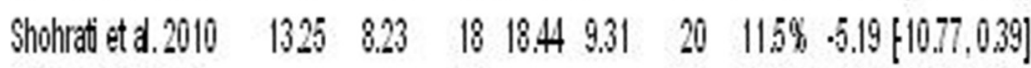

Sultectal $(95 \% \mathrm{Cl}) \quad$ 90 $92.63,0 \% \cdot 2.56[-495,0.017]$

Heterogenenty, Chi ${ }^{2}=1.05, d f=1(P=0.31) ; 2^{2}=48$

Tes tor overall effed: $z=2.10(P=0.04)$

3.12 The redice amourts of TBL(UOCA)

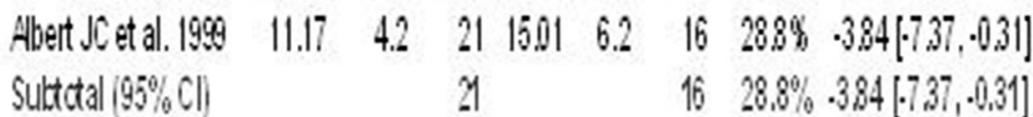

Heterogenety. Notapplicale

Ted tr o o erall effed: $Z=2.13(P=0.03)$

3.1,3 The redice amounts of TBLL (silibirin)

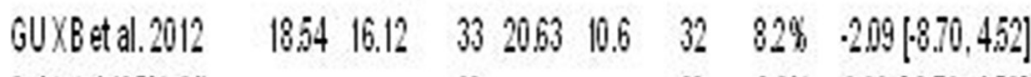

Sultctal $(95 \% \mathrm{Cl}) \quad 33 \quad 32 \quad 82 \% \cdot 2.299[-870,452]$

Heterogenenty. Notapplicdle

Tes tr ocerall effed: $z=0.52(p=0.54)$

Total $(95 \% \mathrm{Cl})$

144

Heterogenenty. Chi ${ }^{2}=1.45, d f=3(P=0.98) ; 1^{2}=0 \%$

Ted to o verall effed: $Z=299(P=0.003)$

Tes tor sabaroud differences: Chi $^{2}=0.41 . \mathrm{df}=2(P=0.82), P=0 \%$

140. $1000 \% \cdot 289[-478, \cdot 1,00]$

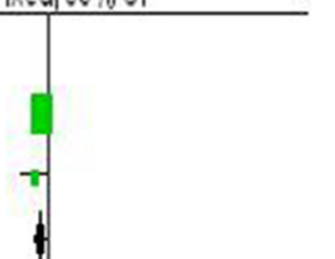

In patients with chronic hepatitis B infection. Data are presented as pooled relative risks using a fixed-effect model and $95 \%$ confidence intervals.

6.7. Effects of Hepatoprotective Agents on Liver Fibrosis Indexes in Patients With Hepatitis B

Three randomized controlled clinical trials reported the effects of hepatoprotective agents on liver fibrosis markers, HA, IV-C and PIIIP. From the three studies, the test and control groups consisted of 121 and 118 subjects, respectively. The heterogeneity between the studies was statistically significant (I2 > 50\%). Thus, a random-effects model was used. The results indicated that hepatoprotective agents were indeed associated with improved indices of hepatic fibrosis compared to placebo: $\mathrm{HA}$ (WMD $=-55.65,95 \% \mathrm{CI}[-75.00,-36.31]), \mathrm{IV}-\mathrm{C}(\mathrm{WMD}=-29.23,95 \% \mathrm{CI}$ $[-41.21,-17.25])$, PIIIP $($ WMD $=-53.79,95 \%$ CI $[-69.03,-38.55])$ (Figure 6).

Four randomized controlled clinical trials reported the effects of combined hepatoprotective agents versus a single agent on the liver fibrosis index, LN. The group 
Figure 4. Meta-Analysis Forest Plots for Effects

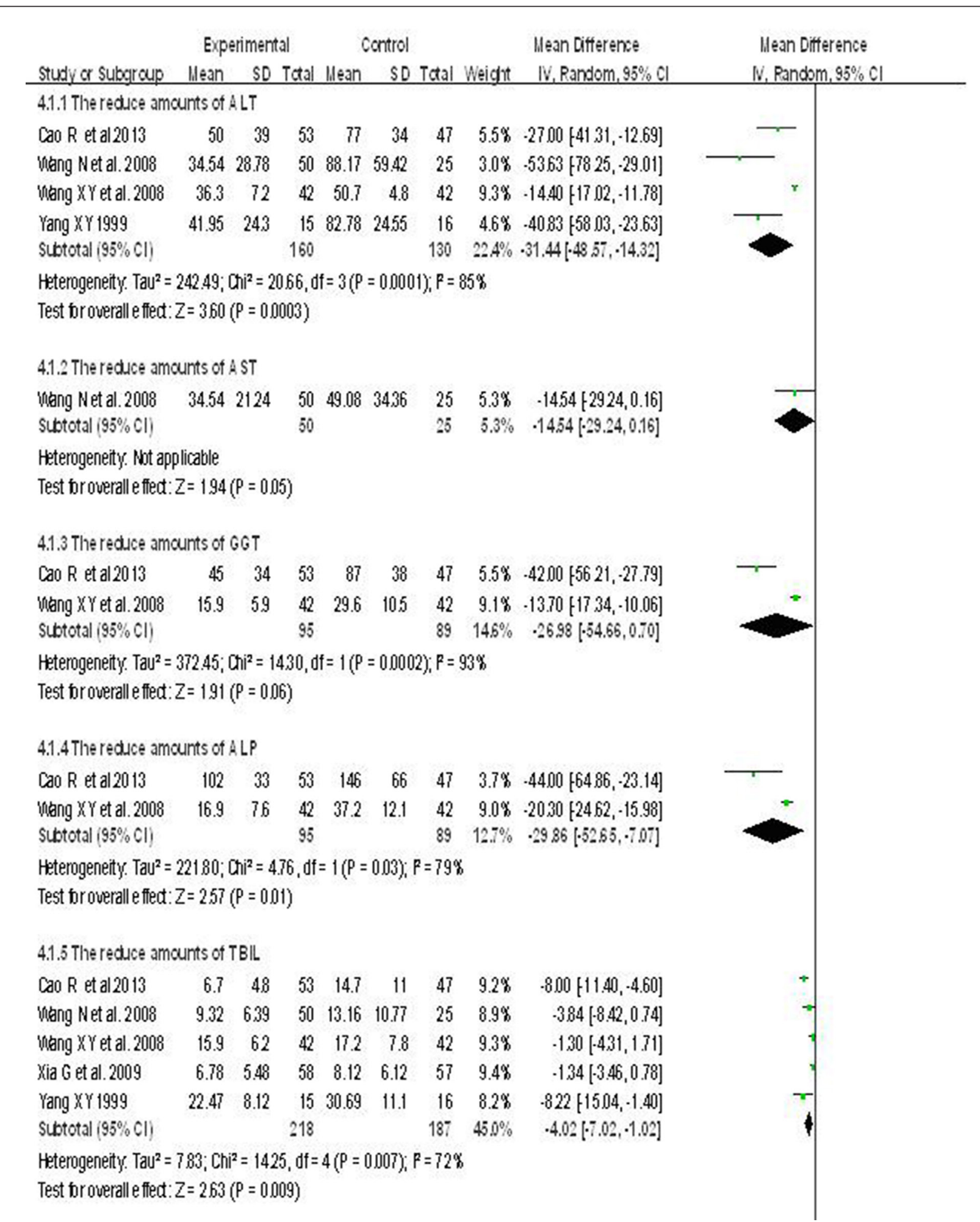

In patients with chronic hepatitis B infection treated with the combination of two liver protective drugs vs. one liver protective drug. Data are presented as pooled mean difference using a random-effect model, and 95\% confidence intervals. 
Long L et al.

representing the combined hepatoprotective agents included 151 subjects, whereas the single hepatoprotective agent group had 148 subjects. There was no significant heterogeneity (I2 < 50\%); therefore, a fixedeffects model was used. Meta-analysis showed that the two hepatoprotective agents was superior to the single one in terms of reducing LN levels (WMD $=-33.91,95 \% \mathrm{CI}$ $[-40.51,-27.31]$ ) (Figure 7).

\subsection{Assessment of Publication Bias}

A Funnel plot analysis of bias among 12 trials on the effects of hepatoprotective agents on normalization of ALT, AST and TBIL was conducted, in patients with hepatitis B (Figure 8). The Funnel plot showed that the distribution of the samples were asymmetrical, suggesting that some of the test methodologies may have been of low quality, and publication bias may have been present.

Figure 5. Meta-Analysis Forest Plots Indicating the Normalization Rates of ALT and TBIL

Experimental Control Odds Ratio Odds Ratio

Study ar Subgroup Everts Tadal Everts Total Weight W.H, Fxed, $95 \% \mathrm{Cl} \quad$ W.H,Fixed,95\% Cl

$5.1,1$ Then normalizationrate of A LT

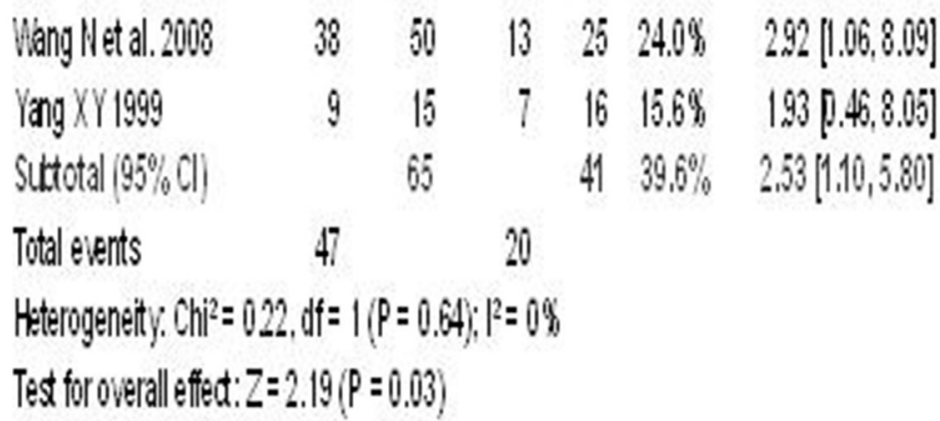

5.12 Thencrmalization rate of TBLL

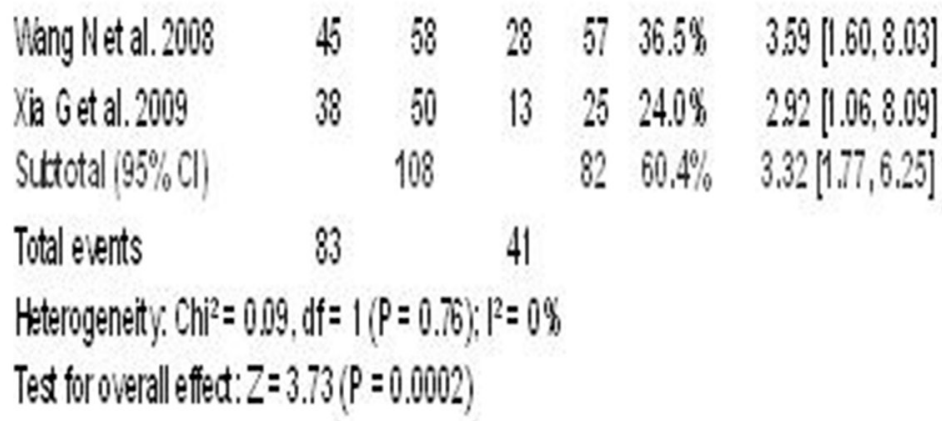

Tatal $(95 \%$ Cl)

Total events

130

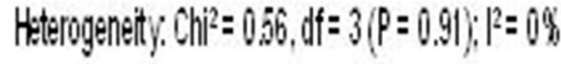

Tes for overall efted: $Z=4.31(P<0.0001)$

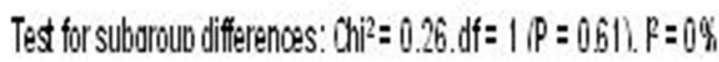
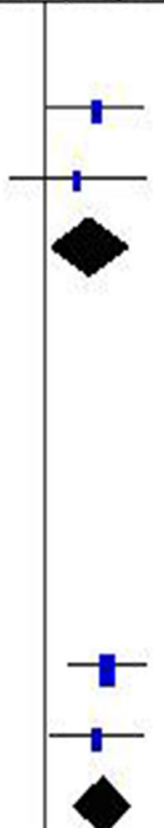

$3,01[182,4,97]$

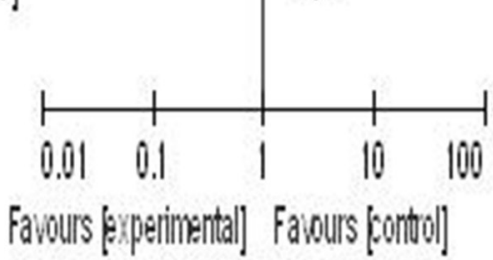

In patients with chronic hepatitis B infection treated with two vs. one hepatoprotective agent. Data are presented as pooled relative risks, adopted fixedeffect model and $95 \%$ confidence intervals, by trial. 
Long L et al.

Figure 6. Meta-Analysis With Forest Plots Effects of two Hepatoprotective Agents vs. a Single Hepatoprotective Agent on Levels of HA, IV-C and PIIIP

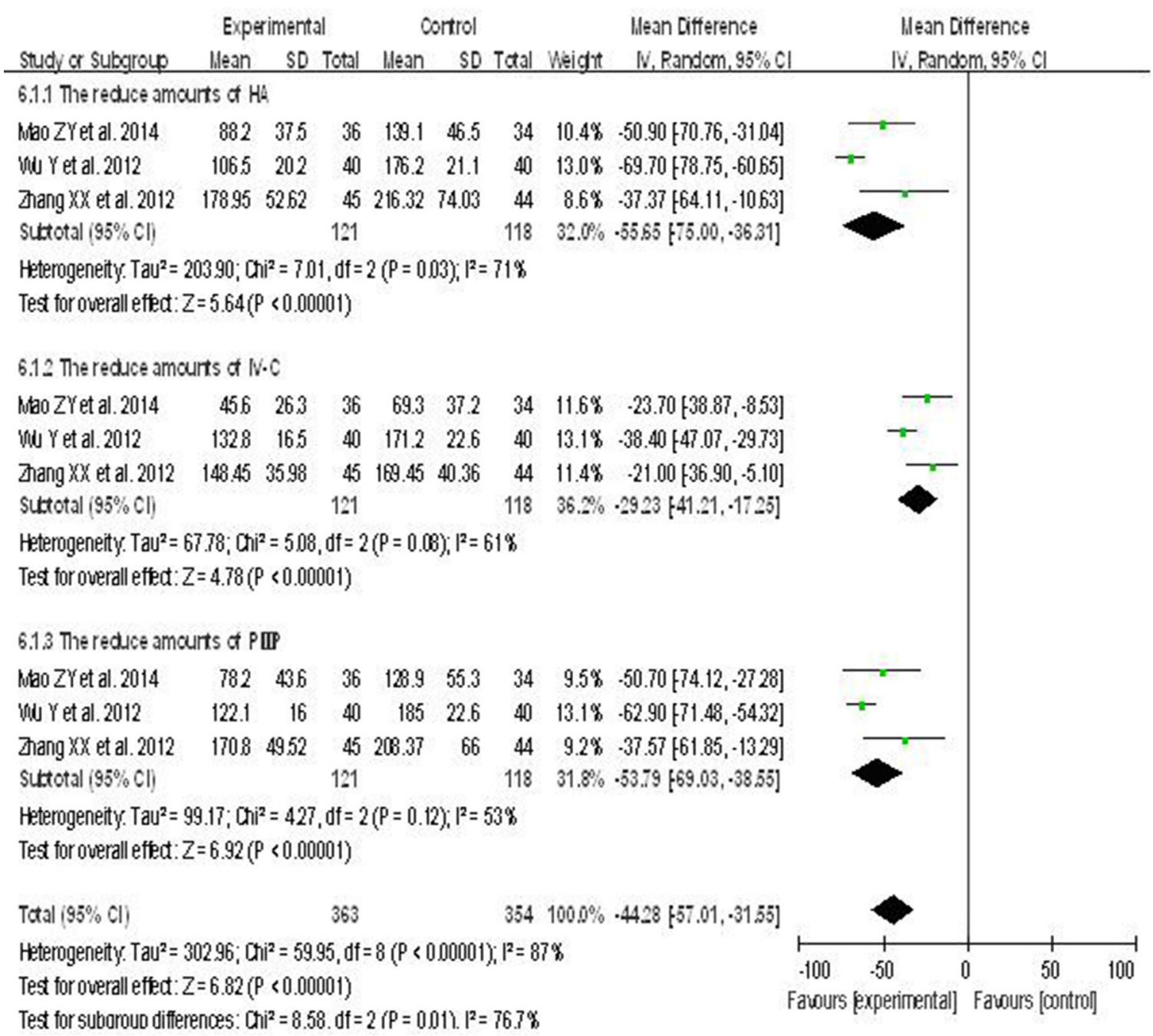

In patients with liver fibrosis. Data are presented as pooled mean difference using a random-effects model and $95 \%$ confidence intervals, by trials.

Figure 7. Meta-Analysis Forest Plots of LN Levels in Patients With Liver Fibrosis Infection Treated with Two vs. one Hepatoprotective Agents

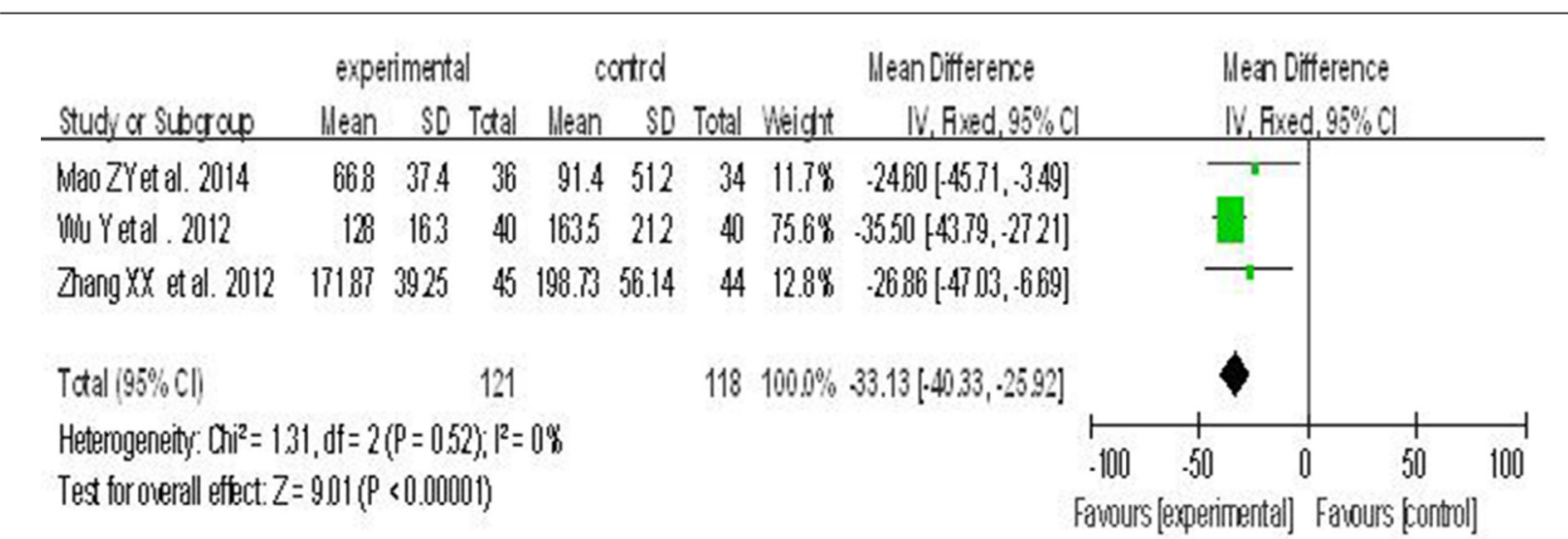

Data are presented as pooled mean difference using a random-effects model, and 95\% confidence intervals. 


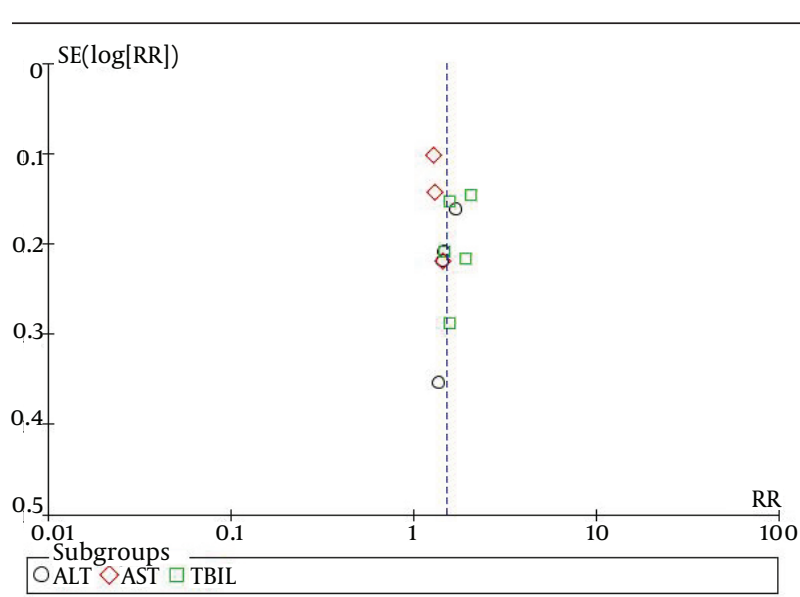

Figure 8. A Funnel plot analysis of the effects of hepatoprotective agents on normalization of ALT, AST and TBIL, in patients with hepatitis B

\section{Discussion}

The current model is expected to maximize long-term treatment of severe liver disease caused by HBV infection to suppress the virus, improve inflammation and necrosis, and deliver adjuvant therapy to manage complications.

The results of the current study showed that after a certain treatment course of a combined hepatoprotective and antiviral drugs, liver function and fibrosis index decreased in most of the subjects. Combination therapy was more effective than a single hepatoprotective agent to reduce liver cell damage, promote the liver cell membrane and promote the recovery of liver function, and it may delay the formation and development of hepatic fibrosis (38). Some studies showed a synergistic effect between hepatoprotective agents and antiviral drugs. It may be related to the improvement in drug tolerance due to hepatoprotective agents in patients with

hepatitis B $(34,40)$. In 2006, Qureshi et al reported that large doses of ursodeoxycholic acid reduces ALT levels in patients with hepatitis B (28). The meta-analysis of the current study showed that acetylcysteine, ursodeoxycholic acid and silibinin significantly reduced ALT, and were a liver function marker in patients with hepatitis B. The reduction in ALT levels by acetylcysteine was better than ursodeoxycholic acid and silibinin. This may be related to the ability of acetylcysteine to inhibit the expression of serum II-18, IFN- $\gamma$ and NO in the patients with hepatitis B. Some studies stated that acetylcysteine should be used, and that it was more beneficial in early stages of liver disease (21).

The limitations of the study included the retrospective nature, variability of the quantity, quality and sources of the hepatoprotective agents, and the variability, and effectiveness of the antiviral agents. High-quality multicenter, large sample, randomized, double-blind and controlled clinical trials are necessary to confirm the current observations.
In conclusion, hepatoprotective drugs can effectively improve serum liver markers in patients with liver fibrosis when combined with antiviral or other hepatoprotective agents.

\section{Acknowledgements}

The current work was supported by the social development research project of Shaanxi science and technology agency (No. 2012k14-04-01) and the project of Xi'an medical college (No. XYFY11-02).

\section{Authors' Contributions}

Authors had equal contribution.

\section{Funding/Support}

The current research was financially supported by Shaanxi Science and Technology Agency (No. 2012k14-0401); the project of Xi'an Medical College affiliated hospital (No. XYFY11-02).

\section{References}

1. Liang GN, Chen LH. Glycyrrhizin injection combined with Danshen injection observe the effect of hepatitis B liver fibrosis. $J$ Tibetan Med. 2010;31(1):24-5.

2. Alavian SM, Tabatabaei SV, Ghadimi T, Beedrapour F, Kafi-Abad SA, Gharehbaghian A, et al. Seroprevalence of Hepatitis B Virus Infection and Its Risk Factors in the West of Iran: A Population-based Study. Int J Prev Med. 2012;3(11):770-5.

3. Bataller R, Brenner DA. Liver fibrosis. I Clin Invest. 2005;115(2):209-18.

4. Friedman SL. Mechanisms of hepatic fibrogenesis. Gastroenterology. 2008;134(6):1655-69.

5. Kim BK, Kim do Y, Park JY, Ahn SH, Chon CY, Kim JK, et al. Validation of FIB-4 and comparison with other simple noninvasive indices for predicting liver fibrosis and cirrhosis in hepatitis B virus-infected patients. Liver Int. 2010;30(4):546-53.

6. Lim YS, Kim WR. The global impact of hepatic fibrosis and endstage liver disease. Clin Liver Dis. 2008;12(4):733-46.

7. Cao R, Hu XD, Cheng H. Observation on the clinical efficiency of adenosine combine with ursodeoxycholic acid in the treatment of chronic hepatitis B with severe jaundice. Chin Hosp Pharm J Dis. 2003;32(6):481-3.

8. Gao Y, Song MZ, Liang CR. Clinical Observation of Ademetionine Combined With Ursodeoxycholic Acid in the Treatment ofChronic Severe Cholestatic Hepatitis. Chin Hosp Pharm Dis. 2013;14(3):68-9.

9. Joo SS, Kang HC, Won TJ, Lee DI. Ursodeoxycholic acid inhibits pro-inflammatory repertoires, IL-1 beta and nitric oxide in rat microglia. Arch Pharm Res. 2003;26(12):1067-73.

10. Fekaj E, Gjata A, Maxhuni M. The effect of ursodeoxycholic acid in liver functional restoration of patients with obstructive jaundice after endoscopic treatment: a prospective, randomized, and controlled study. BMC Surg. 2013;13:38.

11. Boberg KM, Wisloff T, Kjollesdal KS, Stovring H, Kristiansen IS Cost and health consequences of treatment of primary biliary cirrhosis with ursodeoxycholic acid. Aliment Pharmacol Ther 2013;38(7):794-803.

12. Tkacz B, Dworniak D. [Sylimarol in the treatment of acute viral hepatitis]. Wiad Lek. 1983;36(8):613-6.

13. Wei F, Liu SK, Liu XY, Li ZJ, Li B, Zhou YL, et al. Meta-analysis: silymarin and its combination therapy for the treatment of chronic hepatitis B. EurJ Clin Microbiol Infect Dis. 2013;32(5):657-69.

14. Ren BR, Zhao YY, Xu BH, Wu JL, Chen J, Liang CY. Research of silymarin extraction and silibinin purification. Lishizhen Med Materia Med Res. 2012;23(3):655-6. 
15. Feher J, Lengyel G. [Silymarin in the treatment of chronic liver diseases: past and future]. Orv Hetil. 2008;149(51):2413-8.

16. Hoffer E, Baum Y, Tabak A, Taitelman U. N-acetylcysteine increases the glutathione content and protects rat alveolar type II cells against paraquat-induced cytotoxicity. Toxicol Letters. 1996;84(1):7-12.

17. Harrison P, Wendon J, Williams R. Evidence of increased guanylate cyclase activation by acetylcysteine in fulminant hepatic failure. Hepatology.1996;23(5):1067-72.

18. McClain CJ, Price S, Barve S, Devalarja R, Shedlofsky S. Acetaminophen hepatotoxicity: An update. Curr Gastroenterol Rep. 1999;1(1):42-9.

19. Wang N, Shi XF, Guo SH, Zhang DZ, Ren H. [A clinical study of Nacetylcysteine treatment in chronic hepatitis B patients]. Zhonghua Gan Zang Bing Za Zhi. 2008;16(7):487-9.

20. Xia G. The clinical efficacy observation of acetylcysteine injec tion on 58 cases of chronic severe hepatitis B. West Chin Med J 2009;24(5):1239-40.

21. Shi XF, Guo SH, Wu G, Wang ZY, Ren H, Liu Q. The clinical curative effect observation of acetylcysteine injection on 40 cases of chronic hepatitis B. J Chongqing Med Univ. 2005;30(1):115-21.

22. Shohrati M, Dermanaki F, Babaei F, Alavian SM. Evaluation of the effects of oral $\mathrm{N}$-acetylcysteine and a placebo in paraclinical and oxidative stress parameters of patients with chronic hepatitis B. Hepat Mon. 2010;10(2):95-100.

23. Wu G, Guo SH. The Clinic Study of N-Acetylcysteine Injection Therapy to Chronic Hepatitis B. Chongqing Med Univer. 2004;3:25-49.

24. Wang X, Shen S, Li N, Li Y. [Effect of Ursodeoxycholi acid on liver cirrhosis with hepatitis B]. Zhong Nan Da Xue Xue Bao Yi Xue Ban. 2010;35(2):171-5.

25. Fabris P, Tositti G, Mazzella G, Zanetti AR, Nicolin R, Pellizzer G, et al. Effect of ursodeoxycholic acid administration in patients with acute viral hepatitis: a pilot study. Aliment Pharmacol Ther. 1999;13(9):1187-93.

26. Angulo P, Batts KP, Therneau TM, Jorgensen RA, Dickson ER, Lindor KD. Long-term ursodeoxycholic acid delays histological progression in primary biliary cirrhosis. Hepatology.1999;29(3):644-7.

27. CAO R, Hu XD, CHENG H, HUANG S, BAI T, GAN H, et al. Observation on the clinical efficiency of adenosine methionine combined with ursodeoxycholic acid in the treatment of chronic hepatitis B with severe jaundice. Chinese J Hos Pharm. 2013;6:019.
28. Qureshi H, Mehdi I, Ahmed WU, Alam SE. Role of ursodeoxycholic acid in lowering ALT in chronic liver disease. J Pak Med Assoc 2006;56(3):130-1.

29. Ratziu V, de Ledinghen V, Oberti F, Mathurin P, Wartelle-Bladou $\mathrm{C}$, Renou C, et al. A randomized controlled trial of high-dose ursodesoxycholic acid for nonalcoholic steatohepatitis. J Hepatol. 2011;54(5):1011-9.

30. Flisiak R, Prokopowicz D. Effect of misoprostol on serum beta2microglobulin in the course of viral hepatitis B. Eur J Gastroenterol Hepatol.1999;11(11):1227-30.

31. Flisiak R, Prokopowicz D. Effect of misoprostol on the course of viral hepatitis B. Hepatogastroenterology. 1997;44(17):1419-25.

32. Gu XB, Yang XJ, Hua Z, Lu ZH, Zhang B, Zhu YF, et al. Effect of oxymatrine on specific cytotoxic T lymphocyte surface programmed death receptor-1 expression in patients with chronic hepatitis B Chin Med J (Engl). 2012;125(8):1434-8.

33. Bao FY, Xie J. Silybin phospholipid complex combinated with interferon treating hepatitis B. J Cent Plains Med. 2006;33(15):70-1.

34. Bao FY, Qiu PY. Analyzing the adjunctive therapy of silibinin phospholipid complex treat chronic hepatitis B in 86 cases. Shandong Med. 2006;26:26-31.

35. Kim MY, Cho MY, Baik SK, Jeong PH, Suk KT, Jang YO, et al. Beneficial effects of candesartan, an angiotensin-blocking agent, on compensated alcoholic liver fibrosis - a randomized open-label controlled study. Liver Int. 2012;32(6):977-87.

36. Wang H, Zhao YL, Xu KC. [Clinical and pathological study on effects of Qianggan Capsule combined lamivudine on hepatic fibrosis in patients with chronic hepatitis B]. Zhongguo Zhong Xi Yi jie He Za Zhi. 2006;26(11):978-80.

37. Wu Y, Yao DK, Zhu L. [Clinical observation on the safety and efficacy of ursodeoxycholic acid and fuzheng huayu capsule in the treatment of primary biliary cirrhosis]. Zhongguo Zhong Xi Yi Jie He Za Zhi. 2012;32(11):1477-82.

38. Mao ZY, Xiao M, Wu XJ, Tao LG. TanIIA, Oxymatrine combined therapy on liver function in patients with chronic hepatitis $B$ and liver fibrosis. Pract Clin Med.2014;15(2):21-3.

39. Zhou XY, Gao C, Gao XC, Liu XL, Li LH, Wang X. Clinical effects of valsartan on liver fibrosis indexes in patients with alcoholic liver cirrhosis. Chin J Integr Trad Western Med Live Dis. 2014;24(2):85-6.

40. Gou W, Wang YL. To observe the effect of interferon $\alpha-2 b$ combined with silymarin to treat chronic hepatitis B. Clin Hepatol. 2004;5:302. 